\section{Universal and targeted early home visiting: perspectives of public health nurses, managers and mothers}

\author{
Megan Aston, ${ }^{1}$ Sheri Price, ${ }^{1}$ \\ Josephine Etowa, ${ }^{1}$ Adele Vukic, ${ }^{1}$ \\ Linda Young, ${ }^{2}$ Christine Hart, ${ }^{2}$ \\ Emily MacLeod, ${ }^{1}$ Patricia Randel ${ }^{1}$ \\ 'School of Nursing Dalhousie University; \\ ${ }^{2}$ Capital Health District Authority Public \\ Health Services, Dartmouth, Nova Scotia, \\ Canada
}

\section{Abstract}

Early home visits provided by public health nurses (PHNs) around the world have been proven to positively impact physical, social, emotional and mental health outcomes of mothers and babies. Most of the research has focused on home visiting programs delivered by public health nurses and lay home visitors to support at risk or targeted mothers. Little research has been conducted to examine universal home visiting programs for mothers who are perceived to be lower-risk. The purpose of this research was to explore how universal and targeted early home visiting programs for mothers and babies were organized, delivered and experienced through the everyday practices of PHNs, mothers, and managers in one city in Atlantic Canada. Feminist poststructuralism was used to collect and analyze data through semi-structured face-to-face interviews with 16 PHNs, 16 mothers and 4 managers. Personal, social and institutional discourses of program delivery were examined using discourse analysis. Four main themes of the study include: i) understanding targeted and universal programming; ii) health outcomes; iii) building relationships; and iv) exploring a new surveillance. This article will discuss the first theme; understanding targeted and universal programming.

\section{Introduction}

The health of mothers and babies, particularly in the early postpartum period, is the foundation on which life-long health is built, and supporting families during this time is a priority in countries around the world. ${ }^{1-3}$ Home visiting programs delivered by public health nurses (PHNs) and community lay home visitors is one service that provides support for new mothers and their families, beginning the first few months postpartum and sometimes continuing for one to five years depending on health needs. For example, early home visiting (EHV) programs have been proven to positively impact the physical, social, emotional and mental health outcomes of mothers, babies and families. ${ }^{4-10}$ However, the type of home visiting that should be offered continues to be debated. For example, an ongoing discussion for many public health organizations is whether home visiting services should only be offered to targeted mothers perceived to be at risk or whether a more universal home visiting approach should also be offered to all new mothers, regardless of their particular life circumstances or perceptions of risk. A report published in Canada by Sudbury \& District Health Unit ${ }^{11}$ presents a discussion about the importance of offering a combined approach of targeted within universalism when working with particular populations. The World Health Organization (WHO) also supports the practice of ensuring accessibility of services for all new mothers as well as at risk mothers. ${ }^{3}$ In their Cochrane review Jahanfar, Jahnssen, Howard and Dowswell ${ }^{12}$ report the positive effects of both targeted and universal EHV for mothers. However, debate continues around the globe as to how these programs should be offered. While there is ample research evidence to support the effectiveness of targeted EHV programs there has been very little research that has examined universal EHV programs. This gap in current understanding of universal EHV programming and its impact on the lives of mothers and babies calls for research such as our recent study. Specifically, the purpose of the study was to explore how universal and targeted EHV programs for mothers and babies were organized, delivered, and experienced through the everyday practices of PHNs, mothers, and managers in one city in Atlantic Canada. Four main themes emerged. The first theme, the social and institutional construction of targeted and universal programs will be discussed in this paper. All four themes are connected but it is important to be able to present each theme individually in order to provide the reader with an in-depth analysis and discussion. The second theme focuses on how building positive relationships between PHNs and mothers is foundational to attaining positive health outcomes. The third theme addresses how health outcomes continue to be predominantly medicalized thereby creating feelings of invisibility when needs such as feeling confident are seen to be less important. Surveillance was the fourth theme that emerged as the participants spoke about expected relationships of judgment and stigma between health care professionals and mothers.

\section{Materials and Methods}

\section{Background}

The World Health Organization states that
Correspondence: Megan Aston, School of Nursing Dalhousie University, 5869 University Ave Halifax, Nova Scotia, Canada B3H 4R2.

Tel.: 902.494.6376.

E-mail: megan.aston@dal.ca

Key words: public health nurses, mothers, post partum, early home visiting.

Acknowledgements: we would like to acknowledge the Nova Scotia Health Research Foundation and Dalhousie University School of Nursing for financial support of this research.

Contributions: MA, principal investigator, data analysis, significant writing of manuscript; SP, $\mathrm{JE}, \mathrm{AV}$, co-investigator, data analysis, significant writing of manuscript; LY, $\mathrm{CH}$, collaborator, significant writing of manuscript; EM-L, PR, research coordinator, data analysis, significant writing of manuscript.

Conflicts of interest: there are no conflicts of interest.

Conference presentation: some of the information in this manuscript has been presented at two conferences: International Family Nursing Conference, Minneapolis, Minnesota US, June 19-21, 2013, and Community Health Nurses of Canada National, Kelowna BC, June 15-19, 2013.

Received for publication: 27 March 2014.

Revision received: 17 June 2014

Accepted for publication: 17 June 2014.

This work is licensed under a Creative Commons Attribution NonCommercial 3.0 License (CC BYNC 3.0).

(c) Copyright M. Aston et al., 2014

Licensee PAGEPress, Italy

Nursing Reports 2014; 4:3290

doi:10.4081/nursrep.2014.3290

health care must be responsive and accessible to all people who need it. ${ }^{3,13-15}$ Post-partum follow-up care through home visiting is one example of how health services are made accessible to mothers, infants and families. There are numerous examples of EHV programs in countries around the world including but not limited to, Canada, Sweden, Denmark, Australia, the United Kingdom and the United States. ${ }^{16-20}$ However, in Canada and elsewhere accessibility to EHV services differs among new mothers and is influenced by social, cultural and institutional factors.

Public health nursing has a century long history in Canada and began with health promotion and illness prevention for mothers and children through both home and school visiting with a particular focus on poverty and unsanitary living conditions..$^{21-24}$ This strong focus on primary prevention, health promotion and protection for mothers and children con- 
tinues to inform practice today. However, even with this long history the work of PHNs around the world continues to be misunderstood. ${ }^{22,25,26}$ The practice of PHN's has also historically been constructed by western society as women's work and therefore socially constructed to be less valuable than medical or health discourses that interact with mothers in what might be described as scientific or logical. Although the work of PHNs involves complex health assessments that are rigorous, evidence based and scientific ${ }^{22}$ they have also been referred to as mothers' friend. ${ }^{27}$ With the application of a gender based analysis, a health discourse that includes softer values and practices might be deemed as less rigorous and credible compared to medical discourses that define science, measurement and rigor in different ways. These two competing discourses can create an environment that gives less credibility to the work of PHNs and nurses in general. In the 1980's there was a global shift in public health discourse from a socio-ecological approach to a more biomedical, reductionist and clinically driven discourse and this major shift was in conflict with PHNs' socio ecological health promotion and illness prevention practice. ${ }^{22}$ During the 1990's changing notions of public health led to debates about optimal models of service delivery which led PHNs to adopt a more targeted approach to home visiting in North America and the UK.22,25,28-31 Emerging research during this time continued to provide evidence of health inequities and the importance of social determinants of health. ${ }^{32,33}$ As a result, PHNs in Canada and around the world focused on serving the needs of populations perceived to be more vulnerable and at risk.

Several studies have explored the efficacy of targeted programs and have found that they are associated with positive health outcomes such as reduced postpartum depression and an increase in maternal-infant secure attachment; ${ }^{34}$ an increase in parents' infant safety knowledge, a mother's decision to breastfeed and infant primary care visits; ${ }^{35}$ an increase in exclusive breastfeeding; ${ }^{36}$ reduced maltreatment of children; ${ }^{37}$ fewer pregnancies, more time between pregnancies and less time needing aid and food stamps; ${ }^{38}$ development of a positive interpersonal relationship with nurses to effectively address fears of working with health professionals, ${ }^{24}$ feeling empowered about mothering practices; ${ }^{39}$ and the creation of a supportive climate and trust. ${ }^{40}$

One popular targeted program is the NurseFamily Partnership (NFP) developed and researched by Olds ${ }^{41-43}$ and offered by PHNs for single adolescent mothers. This program started in the United States and has spread to the UK and Canada. Others have implemented and conducted research with the NFP program. For example, Donovan et al. ${ }^{44}$ found that there was a reduction in infant deaths and Izzo et al.' $\mathrm{s}^{45}$ randomized controlled trial with 324 low income, young and unmarried first time mothers led to the conclusion that the mothers who received home visitation by registered nurses pre- and post-natally, were better able to cope with stressful life events 15 years later compared to similar mothers who did not receive home visiting. As the research literature demonstrates, there is overwhelming evidence of positive health outcomes associated with EHV programs by PHNs with targeted high-risk mothers. However, there are few studies that focus specifically on universal EHV programs and most of the research on universal programs focuses on paraprofessionals or a combination of paraprofessionals and PHNs. This lack of research evidence can create difficult situations for health care practitioners who have to make decisions about postpartum programs and services. A variety of perspectives about targeted and universal programs were reviewed by Elkan et al. ${ }^{29}$ and the three main issues that they highlighted are as follows: i) A mandate to visit all mothers may create a system whereby mothers in high need will slip through the cracks if there is no targeted screening program; ii) mothers may feel stigmatized when accessing targeted services for high-risk groups, a label with which they would prefer not to be associated; and iii) health issues are not exclusive to populations considered to be at risk and living on the margins.

Findings from our study offer further depth and understanding to these ongoing gaps, concerns and discussions about targeted and universal home visiting programs.

\section{Research setting}

This three-year funded study took place in one of Canada's eastern provinces. At the time of the study Public Health Services provided two postpartum home visiting programs for mothers and babies; targeted for at risk mothers and universal for all other mothers. PHNs screened the majority of mothers prior to discharge from the hospital, using the Parkyn tool that assessed a mother's at risk status. Based on a comprehensive list of determinants of health, mothers who received a high score would be offered services from the targeted program. The program involved an in-depth assessment by a PHN, followed by home visits from a community visitor for up to three years. Mothers who received low scores and were not deemed to be at risk were offered services within the universal program that included telephone support or a home visit depending on their needs. These programs had been in place since 2001 and at the time of the study potential changes to the EHV programs were being explored. This was causing some concerns for both PHNs and managers not knowing what the changes might be.

\section{Methodology}

The methodology used to guide this study was feminist poststructuralism which included Foucauldian concepts of relations of power and discourse analysis as well as feminist concepts of gender, class, race, power, subjectivity and agency. ${ }^{46-50}$ Our analysis began with a focus on individual experiences, personal beliefs, values and practices. We then applied Foucault's complex understanding of power to each individual's experience. This involved a focus on viewing power as relational, situational, shifting and always being negotiated by individuals. This unique way of understanding power is different from Western and more mainstream ways of understanding power as binary, oppositional and often oppressive. Following Foucault's writings, we identified moments of tension or conflict that were initially noted as binary and oppositional and then deconstructed the interaction by looking for different beliefs and values that might exist between individuals, society and institutions. We looked for how individuals understood and were affected by social and institutional constructions of mothering, nursing, health care and home visits. We questioned every day seemingly normal practices to see if there might be other invisible experiences of PHNs and mothers during home visits.

From a feminist point of view, we agreed that participants were experts about their own lives and their descriptions about their experiences were truthful and credible sources of data. The concept of subjectivity allowed us to position participants as self-reflexive and conscious of their own social locations and the concept of agency enabled us to identify moments whereby they questioned, challenged and even changed their own circumstances.

\section{Participant recruitment}

Letters of invitation were sent to all managers and PHNs who conducted early home visits in either the targeted or universal programs. PHNs also provided letters of invitation to mothers who received a home visit. PHNs, managers and mothers were directed to contact the research coordinator if they had questions or were interested in participating in the study. Eligibility criteria included: i) ability to speak and understand English; ii) PHNs had been in their position of work for a minimum of six months; iii) managers of EHV teams who had worked in their position within the past three years and for a minimum of one year; and iv) first time mothers who had received a minimum of one home visit in either of the programs.

The study had a sample size of 36 participants. Out of approximately 30 PHNs who worked at the public health unit 16 participated in the study. PHN participants ranged in age from 32-59 with an average age of 44 and their 
years of experience within the post partum home visiting program ranged from 2.5-12 years. All PHNs had an undergraduate degree in nursing with 5 of the 16 PHNs also holding a Master's degree in Nursing and 2 PHNs were certified lactation consultants. Of the 16 PHN participants, 7 worked with mothers in the targeted program, 9 worked in the universal program and between these two groups of PHN's, 2 worked in both programs. Sixteen mothers also participated in interviews, 6 were in the targeted program and 10 in the universal program. Dyads were not used in this study and therefore PHNs did not know which mothers participated in the study and vice versa. Mothers ranged in age from 18-38 with an average age of 28 . All mothers had a minimum of grade 12 education with 9 mothers also having an undergraduate degree and 2 mothers having a college diploma. One mother was enrolled in university at the time of the interview and 2 others had completed 1 year of postsecondary education. The majority of mother participants (12) lived in urban areas and all were first time mothers. No economic data was collected for this study. Four managers were also interviewed. Recruitment of participants occurred over approximately 6 months and the majority of interviews were conducted shortly thereafter.

\section{Data collection and analysis}

The interviews were conducted in a conversational non-hierarchical manner with a semistructured interview guide. Examples of questions for mothers included How did you find out about the home visiting program? Tell me about your experience during the home visit, What did you and the PHN do during the visit? What did you talk about? How did the visit make you feel? and Was the visit helpful? Why or why not? Similar questions were asked of the PHNs. Mothers were interviewed in their homes and PHNs and managers in a private room at work. All participants signed a consent form when they met the research coordinator for the interview. Interviews were audio recorded and lasted approximately 30-90 min and were then transcribed verbatim by a transcriptionist. All identifying information was removed and pseudonyms replaced real names. In keeping with the principles of discourse analysis, the data analysis entailed a thorough examination of participants' personal beliefs, values and practices as well as close attention to the meaning individuals placed on their experiences. ${ }^{46,51}$ All members of the research team analyzed the first three transcripts and met to identify initial emerging themes. The principle investigator and research coordinator then analyzed the remaining transcripts using discourse analysis. Personal experiences were understood in the context of social and institutional discours- es constructed through relations of power. Examining concepts of subjectivity and agency also provided an understanding of how and why participants acted the way they did based on their beliefs and values about the home visits. ${ }^{47-49}$ The final themes and in-depth analysis were discussed and agreed upon by the full team.

\section{Ethics and rigor}

Ethical approval was obtained from appropriate research ethics boards before recruitment and data analysis began. Rigor and trustworthiness were maintained through accurate transcribing and using memos and notes. Credibility was ensured through regular meetings and discussions with the research team. Transferability of findings were attained by including in-depth analysis and quotations in publications, reports and presentations. Dependability and auditability were established through an audit trail. All participants received comprehensive information on the purpose of the study and signed a consent form. Confidentiality and anonymity involved the names being replaced with pseudonyms and identifying information removed. Data was kept in a locked cabinet to be destroyed five years after completion of the study.

\section{Results}

\section{Understanding targeted}

\section{and universal programming}

Understanding targeted and universal programming was a major theme that emerged through data analysis. This theme refers to how PHNs and mothers experienced and challenged the social construction of targeted and universal programming and includes the following subthemes: i) Screening process; Negotiating dichotomies; ii) Challenging stereotypes and reducing judgments; iii) Bridging the divide between targeted and universal.

\section{Screening process; Negotiating dichotomies}

The Parkyn screening tool was used by PHNs in this study to stream mothers into either the targeted or universal program. If they received a score of 9 or above they were considered to be at risk for unhealthy outcomes and were offered services from the targeted program. PHNs recognized that the screening process was an important stage in defining which type of service a mother received. However, what also emerged throughout the interviews was an understanding of how the construction of risk continued to perpetuate stereotypes about at risk and less risk mothers and ultimately a dichotomy between the two groups of mothers.

So we use the Parkyn Screening Tool. And of course that's to identify mothers who may be at risk for attachment, and other kinds of concerns whether it be financial, domestic abuse, previous violence, small baby. Like all those things that may put her at risk. But what it does [...], is divide us then into the Early Visiting Team [universal] and Enhanced Home Visiting [targeted]. (PHN Universal)

As we deconstructed the term divide and examined the experiences of all participants in the study it became evident that tensions were being experienced when programs were compared and judged. PHNs in the universal program were concerned that their practice was less valued when compared to the targeted program.

Another concern raised by the majority of PHNs was the accuracy and reliability of the screening tool when assessing risk. Many PHNs expressed that the Parkyn screening tool could only identify certain variables and without a home visit the full picture of a mother's environment might be missed.

But I've had people that have come into the Early Team program [universal] that don't have a phone, that have no computer access, are being evicted out of their place, and their Income Assistance is being cut off in 2 weeks. And I go, how did I get you? You know? But if you look at the screening tool, she got a 3. Which is very low... how does that happen? (PHN Universal)

As a result, to overcome these limitations some PHNs described a process of flipping in which a PHN would change a targeted or universal decision based on their own assessment, intuition and perception that occurred when they contacted them by phone within 72 $\mathrm{h}$ of being discharged from the hospital.

[...] it's only a snapshot [in hospital] so it's not an ideal because you're not in the home. But in those situations, sometimes that client may go to the Early Home Visiting [universal] nurse. And then at that point in time, if the nurse goes in, that nurse can reassess and can always flip that client back to us if need be. (PHN Targeted)

PHNs used their assessment skills to overcome the limitations of the Parkyn screening tool. In particular PHNs were concerned about mothers who did not fit the structured and linear definition of at risk on paper. Scoring was often counter to what the PHNs believed would be in the best interest of a mother. Therefore, many of the PHNs in this study challenged the dominant discourse around screening by including holistic assessments that went beyond the more linear and behavior oriented 
scale. One PHN identified issues with screening and described how the targeted program had become too focused on at risk mothers rather than mothers who may need additional support for other reasons.

[...] right now, we're having this struggle between what people are perceiving as an EHV [targeted] client and what's listed on the tool as being a client... So right now, if you are a middle class woman who has a premature baby who was probably going to have developmental delays or something like that, you won't actually score into EHV [targeted]. We want all the low-income, low educated moms that are on Social Assistance. (PHN Universal)

This PHN was challenging the assumptions underlying the tensions between the targeted and universal programs and services in the form of home visits. She believed that those in the targeted group were not the only mothers who needed help. She challenged the definition of risk by shifting the focus of the issue to that of needs. She suggested that all mothers and families should be assessed for where they were at, what they could do for themselves, and what supports they needed. Many PHNs and managers said mothers in both programs were vulnerable, which raises the question What does vulnerable mean? We can see how the terms at risk, vulnerable and need shifted meaning. Because the terms were not always clearly defined, this led to conflicts and challenges when prioritizing needs of mothers and ultimately nursing interventions unique to each mother.

\section{Challenging stereotypes and reducing judgments}

All PHNs spoke about their concern for all mothers feeling judged and in particular those mothers who were screened into the targeted program. The PHNs described how important it was to be non-judgmental despite making judgments about need and risk. As one nurse described:

It's very difficult to do, I'm not perfect at it, but you have to wipe away all your judgments. You really have to be non-judgmental when you do Enhanced Home Visiting [targeted]. (PHN Targeted)

PHNs who worked in the targeted program described how mothers they worked with felt judged by other mothers at drop-in centers who may have more money, a car and were married. Although mothers were not identified at the drop in center as being in the targeted or universal program, mothers of lower socio-economic status were perceived differently. For example:

A lot of my clients have gone there [drop-in centers] and unfortunately they felt looked down upon... They just didn't feel welcome[d] there. (PHN Targeted)

Mothers from both the targeted and universal programs spoke about how they anticipated feeling judged by their PHN and expressed initial worries or concerns about having a clean and tidy home or their personal appearance. Several mothers spoke about fears. For example, one mother from the targeted group said:

I was afraid that being a new mom, I might do something wrong [...] Like someone coming in and keeping an eye on me. And I didn't want to be watched... I don't want somebody coming into my house and telling me I don't have the right to have my kids. That's scary. (Mother Targeted)

Based on the Parkyn scores mothers who screened into the targeted program were predominantly lower socio-economic status, sometimes single and sometimes had lower education. From a health promotion, population focused perspective, most health care professionals would agree that services should first be provided to these marginalized at risk mothers who did not have access to food, housing, supportive parenting role models, education or employment. However, what is often missed is a discussion about how to address a mother's feelings of being judged, stereotyped and stigmatized when labeled at risk.

Lower class, lower education and single mothers have been historically and socially constructed to be less than. This has partly been created through oppositional discourses that focus on economics and education. Those who are seen to be less educated or less financially stable are perceived negatively. Even though the intent of the program was to provide support to mothers who had less than others such as access to services, education or socio economic status, it was also evident that institutional programs by virtue of the programming itself continued to perpetuate negative stereotypes. PHNs and mothers in our study were keenly aware of these social stereotypes. Each of the PHNs described how they addressed these stereotypes with mothers and worked in very purposeful ways to minimize feelings of judgment.

It's not something where we mention 'the program.' That type of language can sometimes scare clients, especially clients who don't trust programs or don't trust healthcare systems. So a lot of that first phone call is just checking in to see what the mom needs. (PHN Targeted)

I think with Early Team [universal] because some of the population is a bit more middle to upper class, I think we wear a little bit more of a professional approach in terms of being the expert and that kind of stuff. And with EHV [targeted], I feel like I need to be a nurse but also show that I'm a person too [...] (PHN Targeted and Universal)

Most of the PHNs in this study discussed how they worked with mothers differently between the two programs. In particular, many PHNs used different techniques and ways of interacting with mothers in the targeted program to make sure they felt comfortable and not judged. As the quotes above demonstrate, the PHNs did not start building the relationship by talking about the program. Many of the PHNs shared similar examples of how they paid close attention to their communication style and were very careful with the language they used. The majority of PHNs spoke about the importance of building trust with all mothers but in particular with mothers who may have difficulty trusting health care professionals. The example provided above shows how one PHN incorporated being personal as well as professional knowing that this was an important element of establishing a positive relationship with mothers. As part of their everyday practices, the majority of PHNs in the study critically assessed the social discourses, stereotypes and stigma of each mother so that they could then effectively work with them to develop respectful and trusting relationships. Even though there were common postpartum issues experienced by mothers, PHNs also spoke about the importance of focusing on unique and contextualized needs. Being aware of and attending to the socially constructed stereotypes of at risk and less risk mothers described how PHNs were able to challenge the negative effects of organizing mothers into these two groups.

\section{Bridging the divide between targeted and universal}

The majority of PHNs described a distinct divide between the targeted and universal programs where the targeted program was seen to be more important because it was responding to the needs of vulnerable mothers who were perceived to require different or more help than universal mothers. A health discourse focusing primarily on risky behaviors at the expense of more general postpartum concerns continued to perpetuate hegemonic beliefs that the universal program was less valued. For example, one PHN said:

... For the past 2 or 3 years, we've been hearing language like the home visiting part of the Universal program is a Cadillac service and it's too expensive to be continuing on in the way that it's continuing on.' (PHN Universal)

The majority of PHNs were aware of this divide and expressed concern that if the universal program was eliminated due to lack of 
perceived value and need, then many mothers who might normally access the universal program would fall through the cracks. At the time of the study PHNs were providing universal home visits to all mothers who wanted this service and they believed they were making a difference to improve health outcomes for these mothers and were therefore very concerned that there might not be appropriate services elsewhere in the community if the program was eliminated.

They say they want to get the marginalized populations and they say [...] that's where the funding is going towards, EHV [targeted]. So hopefully nothing will change in that respect but I'm not sure how the Early Team I universal] people are going to fit into that...I'm just worried that people are going to fall through the cracks. And I think once the community is more aware of what's happening, like the [hospital] and the family doctors, if we do make changes to our program, they're going to have to pick up their services. And they don't have the staff either to do that, right. (PHN Targeted and Universal)

The majority of PHNs spoke about the difference home visiting services made for mothers in the universal program and their apprehension with the prospect of its elimination. In particular they stated that there were inadequate amounts of postpartum community supports in place and they discussed the lack of evidence available to make such a decision. There had been one evaluation done to measure the impact of suspending the universal home visiting program during the H1N1 crisis, however, not everyone agreed that one evaluation was enough evidence to support reducing or closing the program. Many PHNs echoed the opinion of one PHN who expressed her concern in the following quote.

So with the changes with Public Health, they've basically done research and said that the Early Team luniversal] isn't making the impact that they would like to make on their community once they did this big research study around H1N1. So based on this one specific study in a time of crisis, which some people think is maybe not a true, accurate reflection of the program, they've decided that they have to reinvent the Early Team [universal]. So they're going to change the services completely. (PHN Targeted and Univer sal)

Throughout the interviews we heard numerous examples from PHNs and mothers in both programs about how they believed the home visits did make a significant and positive difference. Similar health outcomes included feeling more confident, normal, and empowered, as well as experiencing reduced stress and anxiety. Positive breastfeeding support and success were also described by mothers and PHNs in both programs. Therefore, when it appeared that the universal home visiting program might be eliminated or reduced, PHNs described feeling devalued as they felt their practice had been invisible, misrepresented or misunderstood.

So personally that makes me feel devalued. It makes what I have been doing for the past $x$ number of years appear to be not important. Which goes totally against my grain, you know, because I wouldn't be so passionate about what I do if I felt it was useless and it was no good and it wasn't important. And it's only when after the visit and the feedback you get from the moms or the dads that reinforces yes, this is why I'm doing this. This is truly making a difference in these individual lives. (PHN Universal)

All of the PHNs described experiencing tensions and all of the PHNs in the universal program did not feel their work was understood or valued by managers and other nurses who had not worked in the universal program. Those who worked in the universal home visiting program valued the work because they had witnessed how their support had made a difference for mothers and families. PHNs working in the universal program spoke about how they continued to resist negative attitudes and misunderstandings they felt from their colleagues and other health care professionals. This resistance is an example of how PHNs attempted to challenge the different perceptions of other health care providers who they believed did not fully understand their practice.

Although there were many similarities in terms of health outcomes between the two programs, PHNs and managers also recognized significant differences. For example, PHNs described how mothers in the targeted program needed to focus more on financial and housing issues whereas mothers in the universal program were able to focus more on breastfeeding.

And in their [Universal PHNs] situations, most clients need visits for breastfeeding support. That would be the bulk of what they're providing. Most of my clients [targeted], they breastfeed and they do it because they just do it. They don't get caught up in everything else going on. So they either do a really great job at breastfeeding or they're pumping and giving breast milk, or they formula feed. Feedings are not something that the clients I support get caught up in usually because there's too much other stuff going. (PHN Targeted)
With a mandate to increase services to $\mathrm{vul}$ nerable populations and the ability of PHNs to assess for higher risk using the Parkyn tool and their assessment skills during home visits, it was clear that the majority of PHNs and managers agreed that priority needed to be given to targeted mothers. However, it was also clear that questions still remained about how mothers categorized as universal should be supported. Evaluations of the targeted program had been implemented but no evaluations of the universal program had been conducted. A lack of evaluations about the universal program continued to perpetuate misunderstandings about the program as well as feelings by PHNs that their work in this program was invisible. It is also difficult to measure health promotion and illness prevention in the short term and is an ongoing struggle for health units across North America. There was a clear hierarchy and tension between the two programs that was articulated by PHNs and managers in this study. However, we suggest that these moments of tension and different values and beliefs about home visiting can be used as opportunities for further discussion and exploration of how home visiting programs need to be understood and evaluated.

\section{Discussion}

Offering both targeted and universal programs to all mothers could be interpreted as inclusive programming that recognizes all mothers may experience difficulties during the postpartum period. However, as demonstrated through participants' experiences it is evident that having two distinct programs has institutionally constructed a dichotomy on many levels. Not surprisingly, the institutionally constructed dichotomy created tensions between beliefs and values about each program. Although some of the PHNs generally believed that middle class, well-educated mothers were better positioned to seek out supports on their own and coped better than lower socioeconomic mothers, the majority of PHNs challenged this belief. They provided examples of higher socioeconomic mothers they visited who desperately needed their support. This dichotomy and debate is not unique to our study. Historically, Western discourses on class and mothering have perpetuated a dominant belief that because middle class well educated mothers have better access to services compared to lower educated and socioeconomic mothers, they will experience better health outcomes. ${ }^{11,52}$ The accuracy of this belief needs to be questioned, particularly in light of the fact that there is little research conducted on universal home visiting. In order to better understand this debate the meaning of 
better health outcomes needs to be explored.

The question of what traditionally has been considered and valued as health outcomes of targeted and universal programs is significant. It has been particularly challenging to find documentation of health outcomes for universal mothers, but in our study, PHNs and mothers have provided many examples of similar health outcomes between mothers in both programs, such as empowerment, confidence and reduced stress and anxiety. The majority of PHNs, managers and mothers in both programs believed home visits were beneficial and made a difference. Many of the PHNs in this study, particularly those in the universal program spoke about how their home visiting practices were often invisible and misunderstood. The invisibility of nursing practice in general has been written about by many authors ${ }^{53-56}$ and continues to be a contributing factor to the socially constructed oppression of nursing. Meagher-Stewart et al ${ }^{25}$ argue that clear documentation of practices (interventions) by PHNs along with health outcomes would help make the practice of nursing more visible. We argue that it would also help us to understand what mothers and PHNs value as important health outcomes and how to attain them.

\section{Limitations}

While the sample size of 36 participants was significant for a qualitative study and common themes that arose through the analysis can potentially be transferable to similar settings we would suggest that a limitation of the study is a lack of diversity in the sample in terms of gender, sexuality, race, culture, abilities, etc. Therefore we recommend that similar studies be conducted to examine the experiences of a variety of mothers, fathers and guardians who use targeted and universal home visiting programs.

\section{Conclusions}

The different beliefs, values and practices expressed by PHNs and mothers within each of the programs came together to create tensions of uncertainty, disagreement, and at times agreement. Although this study was conducted during a stressful time of change, the timing provided an opportunity to discuss and critique the complex issues of targeted and universal EHV. We offer our research findings from the first hand experiences of frontline PHNs, mothers and managers as evidence for ongoing dialogue on promising models or best practices of early home visiting for all new mothers and their families. Positive change in this area of postpartum care is necessary to break down the perpetuating stereotypes and inequities mothers encounter in the health care system.

\section{References}

1. Engle PL, Black MM, Behrman JR, et al. Strategies to avoid the loss of development potential in more than 200 million children in the developing world. Lancet 2007;369:229-42.

2. Blackman JA. Early intervention: A global perspective. Infant Young Child 2002;15:11-9.

3. World Health Organization. WHO recommendations on postnatal care of the mother and newborn - 2013. Geneva: World Health Organization; 2013.

4. Kersten-Alvarez LE, Hosman CM, RiksenWalraven JM, et al. Long-term effects of a home-visiting intervention for depressed mothers and their infants. J Child Psychol Psychiatry 2010;51:1160-70.

5. Nievar MA, Van Egeren LA, Pollard S. A meta-analysis of home visiting programs: Moderators of improvements in maternal behavior. Infant Ment Health J 2010;31: 499-520.

6. Olds DL, Kitzman HJ, Cole RE, et al. Enduring effects of prenatal and infancy home visiting by nurses on maternal life course and government spending: Followup of a randomized trial among children at age 12 years. Arch Pediatr Adolesc Med 2010;164:419-24.

7. Vanderburg S, Wright L, Boston S, et al. Maternal child home visiting program improves nursing practice for screening of woman abuse. Public Health Nurs 2010; 27:347-52.

8. Sharps PW, Campbell J, Baty ML, et al. Current evidence on perinatal home visiting and intimate partner violence. $\mathrm{J}$ Obstet Gynecol Neonatal Nurs 2008;37:480-91.

9. Plews C, Bryar R, Closs J. Clients' perceptions of support received from health visitors during home visits. J Clin Nurs 2005; 14:789-97.

10. Sweet MA, Appelbaum MI. Is home visiting an effective strategy? A meta-analytic review of home visiting programs for families with young children. Child Dev 2004;75:1435-56.

11. Sudbury \& District Health Unit. 10 promising practices to guide local public health practice to reduce social inequities in health. Sudbury, ON; 2011. Available from: http://www.sdhu.com/uploads/content/listings/10PromisingPractices.pdf

12. Jahanfar S, Janssen PA, Howard LM, Dowswell T. Interventions for preventing or reducing domestic violence against pregnant women (review). Cochrane Database Syst Rev 2013;2:CD009414.

13. World Health Organization. The world health report 2000: Health systems: Improving performance. Geneva: World
Health Organization; 2000.

14. World Health Organization. Responsiveness; 2001. Available from: http://www. who.int/responsiveness/en/

15. World Health Organization, Office of the UN High Commissioner for Human Rights. The right to health - Joint Fact Sheet WHO/OHCHR/323; August 2007. Geneva: World Health Organization; 2007. Available from: http://www.who.int/mediacentre/factsheets/fs323_en.pdf

16. Kronborg H, Vath M, Kristensen I. The effect of early postpartum home visits by health visitors: a natural experiment. Public Health Nurs 2012;29:289-301.

17. Henderson S. Community child health (CCH) nurses' experience of home visits for new mothers: a quality improvement project. Contemp Nurse 2009;34:66-76.

18. Baggens CAL. The institution enters the family home: Home visits in Sweden to new parents by the child health care nurse. J Community Health Nurs 2004;21: 15-27.

19. Bull J, McCormick G, Swann C, Mulvihill C. Ante- and post-natal home-visiting programmes: a review of reviews [Evidence Briefing]. London: Health Development Agency; 2004.

20. Kendrick D, Elkan R, Hewitt M, et al. Does home visiting improve parenting and the quality of the home environment? A systematic review and meta analysis. Arch Dis Child 2000;82:443-51.

21. Aston M, Meagher-Stewart D, Edwards N, et al. Public health nurses' primary health care practice: Strategies for fostering citizen participation. J Community Health Nurs 2009;26:24-34.

22. Stamler LL, Yiu L. Community health nursing: a Canadian perspective. 3rd ed. Toronto, ON: Pearson Prentice Hall; 2011.

23. MacLellan-Peters J, Aston M. Don't blame low-income mothers! understanding lowincome mothers' socio-ecological circumstances in relation to health status. J Assoc Res Mothering 2006;11:98-110

24. Jack SM, DiCenso A, Lohfeld L. A theory of maternal engagement with public health nurses and family visitors. J Adv Nurs 2005;49:182-90.

25. Meagher-Stewart D, Aston M, Edwards N, et al. Fostering citizen participation and collaborative practice: tapping the voices and wisdom of public health nurses in Nova Scotia. Halifax NS: Dalhousie University, Research Report; 2004.

26. Yiu L, Horsburgh M. Rebuilding public health nursing practice: a Canadian perspective. Public Health Nurs 1989;6:16973.

27. Davies C. The health visitor as mother's friend: A woman's place in public health, 1900-1914. Soc Hist Med 1998;1:39-59. 
28. Hall C, White S. Looking inside professional practice: discourse, narrative and ethnographic approaches to social work and counselling. Qual Soc Work 2005;4:379-90.

29. Elkan R, Robinson J, Williams D, et al. Universal vs. selective services: the case of British health visiting. J Adv Nurs 2001; 33:113-9.

30. Olds DL. The nurse home visitation program. Future Child 1999;9:190-1.

31. Twinn S, Cowley S. The principles of health visiting: a re-examination. London: Health Visitors Association/United Kingdom Standing Conference on Health Visitor Education; 1992.

32. PHAC Public Health Agency of Canada. What determines health? 2010 [cited January 28 2011]. Available from: http://www.phac-aspc.gc.ca/ph-sp/determinants/index-eng.php

33. Ashton J, Seymour H. The new public health: the Liverpool experience. Milton Keynes, New York: Open University Press; 1988.

34. Armstrong KL, Fraser JA, Dadds MR, et al. A randomized, controlled trial of nurse home visiting to vulnerable families with newborns. J Paediatr Child Health 1999; 35:237-44.

35. Hedges S, Simmes D, Martinez A, et al. Programs that work! A home visitation program welcomes home first-time moms and their infants. Home Healthc Nurse 2005;23:286-9.

36. Bashour HN, Kharouf MH, Abdulsalam AA, et al. 2008. Effect of postnatal home visits on maternal/infant outcomes in Syria: A randomized controlled trial. Public Health Nurs 2008;25:115-25.

37. Eckenrode J, Ganzel B, Henderson CR, et al. Preventing child abuse and neglect with a program of nurse home visitation: the limiting effects of domestic violence. JAMA 2000;284:1385-91.

38. Kitzman H, Olds DL, Sidora K, et al. Enduring effects of nurse home visitation on maternal life course: A 3-year follow-up of a randomized trial. JAMA 2000; 283:1983-9.

39. Aston M, Meagher-Stewart D, SheppardLemoine D, et al. Practice applications of research family health nursing and empowering relationships. Pediatr Nurs 2006;32:61-7.

40. Jansson A, Petersson K, Udén G. Nurses' first encounters with parents of new-born children - public health nurses' views of a good meeting. J Clin Nurs 2001;10:140-51.

41. Olds DL, Robinson J, O'Brien R, et al. Home visiting by paraprofessionals and by nurses: A randomized, controlled trial. Pediatrics 2002;110:486-96.

42. Olds DL. The nurse-family partnership: an evidence based preventive intervention. Infant Ment Health J 2006;27:5-25.

43. Olds DL. Preventing crime with prenatal and infant support of parents: the nursefamily partnership. Vict Offender 2007; 2:205-25

44. Donovan EF, Ammerman RT, Besl J, et al. Intensive home visiting is associated with decreased risk of infant death. Pediatrics 2007;119:1145-51.

45. Izzo C, Eckenrode J, Smith E, et al. Reducing the impact of uncontrollable stressful life events through a program of nurse home visitation for new parents. Prev Sci 6:269-74.

46. Cheek J. Postmodern and poststructural approaches to nursing research. Thousand Oaks California: Sage Publications; 2000.

47. Butler J. Contingent foundations: feminism and the question of "postmodernism”. In: Butler J, Scott J, eds.
Feminists theorize the political. New York: Routledge, Chapman and Hall; 1992. pp 321.

48. Butler J. Giving an account of oneself. 1st ed. New York: Fordham University Press; 2005.

49. Scott J. Experience. In: Butler J, Scott J, eds. Feminists theorize the political. New York: Routledge, Chapman and Hall; 1992. pp 22-40.

50. Foucault M. The subject and power. In: Dreyfus HL, Rainbow P, eds. Michel Foucault, beyond structuralism and hermeneutics, 2nd ed. Chicago: University of Chicago Press; 1983. pp 208-226.

51. Powers P. The methodology of discourse analysis. Sudbury, MA: Jones and Bartlett; 2001.

52. Canadian Institute for Health Information (CIHI). Reducing gaps in health: a focus on socio-economic status in urban Canada. Ottawa: CIHI; 2008.

53. Wilson PM, Brooks F, Procter S, et al. The nursing contribution to chronic disease management: a case of public expectation? Qualitative findings from a multiple case study design in England and Wales. Int J Nurs Stud 2012;49:2-14.

54. Boyle DA. The invisibility of nursing: implications from an analysis of national cancer institute - designated comprehensive cancer center web sites. Oncol Nurs Forum 2010;37:E75-83.

55. Community Health Nursing Association of Canada (CHNAC). Canadian community health nursing standards of practice. Toronto: CHNAC; 2003.

56. Clark J. The international classification for nursing practice project. Online $\mathrm{J}$ Issues Nurs 1998;3:Manuscript 3. 